\title{
Feeding common carp fish (cyprinus carpio) on natural foods (algae, phytoplankton, zooplankton and others) on tigris river in mosul dam / duhok, Kurdistan region of Iraq
}

\begin{abstract}
This study is the only study research that has been done on Tigris River in Mosul Dam (Duhok Governorate, Kurdistan Region of Iraq). The main aspect is to Keep Common Carp Fish in Ceramic pond without feeding them any Artificial Feed (Feed concentrate); only depending on natural feeds (algae, Phytoplankton and Zooplankton). At the beginning we thought that fish will lose their weight because of consuming the storage of energy, carbohydrates and others nutrients from muscle and other parts of body, but the result shows opposite, and it increases body weight slightly. This indicates that the water contains many natural foods (algae, phytoplankton, zooplankton and others). Perhaps this reflects types, level and source of water, plankton variety to name but a few of the variables that could be investigated. Other studies could examine the following. It also led us to follow up the research, recording more data and continuing research in the future.
\end{abstract}

Volume 4 Issue 3 - 2016

\section{Shokri Omar Mustafa, Dasthal Mami Ibrahim Koramarky, Sarmad Ali Salih, Nashwan Fadhil Safar, Ayiad Ahmed Alkhiro Mustafa \\ General Directorate of Agriculture, Iraq}

\begin{abstract}
Correspondence: Shokri Omar Mustafa, Head of the Fish Resources Department at the General Directorate of Agriculture, Duhok city, Kurdistan Region, Iraq, Tel 009647504986902,Email shokri.mustafa@quconnectedu.au
\end{abstract}

Received: November 09, 2015 | Published: May 02, 2016

Keywords: Live food, Carp fish, Tigris river, Artificial feed, Algae, Phytoplankton, Zooplankton

\section{Introduction}

Live Food is the best food you can possibly feed to fish. It is natural. It is healthy. It is a money saver. Most anyone that breeds more difficult fish will tell you live food gives healthier fry, more successful spawns, and better coloration than any prepared food on the market. Algae are essentially food come from Green water that grows on suspended phosphates and silicates in the water column. It is a perfect food for the smallest of fry and is also great for feeding Daphnia and other live foods.

This research is the only research that has been done on Tigris River and it needs more study should have be done on it because the climate change has already impact on it and it appear a new species of fish. The Tigris (targris) is the eastern member of the two great rivers that define Mesopotamia, the other being the Euphrates. The river flows south from the mountains of southeastern Turkey through Iraq and empties itself into the Persian Gulf.

The Tigris is $1,850 \mathrm{~km}$ long, rising in the Taurus Mountains of eastern Turkey about $25 \mathrm{~km}$ southeast of the city of Elazig and about $30 \mathrm{~km}$ from the headwaters of the Euphrates. The river then flows for $400 \mathrm{~km}$ through Turkish territory before becoming the border between Syria and Turkey. This stretch of $44 \mathrm{~km}$ is the only part of the river that is located in Syria.

Mosul Dam, in Kurdish: (BêndavaMûsil), Chambarakat Dam, formerly known is the largest dam in Iraq. It is located on the Western of Duhok Governorate and in the western governorate of Ninawa, upstream of the city of Mosul. At full capacity, the hydroelectric dam holds about 11.1 cubic kilometres $(2.7 \mathrm{cu} \mathrm{mi})$ of water and provides electricity to the 1.7 million residents of Duhok and Mosul. The dam's main 750 megawatts $(1,010,000 \mathrm{hp})$ power station contains four 187.5 megawatts $(251,400 \mathrm{hp})$ Francis turbine-generators. Apumped-storage hydroelectricity power plant with a capacity of 250 megawatts $(340,000 \mathrm{hp})$ and a run-of-the-river dam downstream with a 62-megawatt $(83,000 \mathrm{hp})$ capacity also belong to the Mosul Dam scheme. It is ranked as the fourth largest dam in the Middle East, measured by reserve capacity, capturing snowmelt from Turkey, some 70 miles $(110 \mathrm{~km})$ north. Built on a karst foundation, concerns over the dam's instability have led to major remediation and rehabilitation efforts since the 2003 invasion of Iraq.

It is selected the part of the Dam that located at the beginning of the Tigris River (Duhok Governorate) because of the safety and fresh and clean water. Furthermore, this part is consider the best part of raising fish with cage fish culture because we set up many circle cage fish culture on it. Also, we used Fish hatchery pond (Indoor), all these reason help us to succeed our study.

It has been chosen (151 days) for this study (6/11/2014 to 6/4/2015) because the Common Carp Fish at (90 days) will consume crude fat and muscle from their body and at (100-120 days) might be dead. Fortunately, after this period (151 days) it shows that the water contains certain of algae, phytoplankton, zooplankton, and other sin previous study showed and diagnosed that it contains about (42 type) of phytoplankton that has conducted at the University of Mosul. For all these reasons we decided to conduct this study at Mosul Dam (Khank- Sumeel- Duhok Governorate, Kurdistan Region of Iraq).

\section{Materials and methods}

The study is conducted at Carp Fish hatchery in (Khank- SumeelDuhok Governorate, Kurdistan Region of Iraq). It used their pond (Indoor) that belongs to the Ministry of Agriculture and Water Resources in Kurdistan Region of Iraq (General Directorate of Agriculture - Fish Resources Department).

They have been chosen two groups of male of common carp at about two years ago with above three KG weight, because the female 
contain eggs and it might influence on weight. The study should select three factors but it have chosen two factors because of small space of ceramic pond indoor fish hatchery, and we just want it to know the level of natural food in the Tigris River water. The main source of water supply is from Tigris River into a big concrete bond with (200 M3 water) then into a small pellet tank with (2 M3 water). The capacity of each ceramic pond is (2.8 M3 water), each pond joined tube with valve to control the amount of water to inlet pond, and we decided to set on $3 \mathrm{~L} / \mathrm{M}$.

It divided fish into two group, one group include (6 fish) with weight $(18.8 \mathrm{Kg})$, and the two group include ( 9 fish) with weight $(27.5$ $\mathrm{Kg}$ ). Furthermore, the water is supply into ceramic pond with level (3L/Min).

\section{Results}

Throughout the period (151 days), it indicated that (Table $1 \& 2$ ) the weight of fish increased slightly even the differences of number of fish in each ceramic pond with similar amount of supply water $(3 \mathrm{~L} /$ Min) in both ceramic ponds (Figure 1-6).

Table I (Average weight of fish -Kg)

\begin{tabular}{lllllll}
\hline Group & $\mathbf{6} / \mathbf{I} \mathbf{1 / 2 0 1 5}$ & $\mathbf{6 / 1 2 / 2 0 1 5}$ & $\mathbf{6 / 1 / 2 0 1 5}$ & $\mathbf{6 / 2 / 2 0 1 5}$ & $\mathbf{6 / 3 / 2 0 1 5}$ & $\mathbf{6 / 4 / 2 0 1 5}$ \\
\hline $\mathrm{I}$ & 3.15 & 3.2 & 3.24 & 3.28 & 3.3 & 3.36 \\
2 & 3.05 & 3.1 & 3.13 & 3.17 & 3.19 & 3.24 \\
\hline
\end{tabular}

Table 2 (Total weight of fish - Kg)

\begin{tabular}{lllllll} 
Group & $6 / 1 I / 2015$ & $6 / 12 / 2014$ & $6 / 1 / 2015$ & $6 / 2 / 2015$ & $6 / 3 / 2015$ & $6 / 4 / 2015$ \\
\hline$I$ & 18.9 & $19.2 I$ & 19.49 & 19.69 & 19.84 & 20.21 \\
2 & 27.5 & 27.95 & 28.28 & 28.53 & 28.71 & 29.22
\end{tabular}

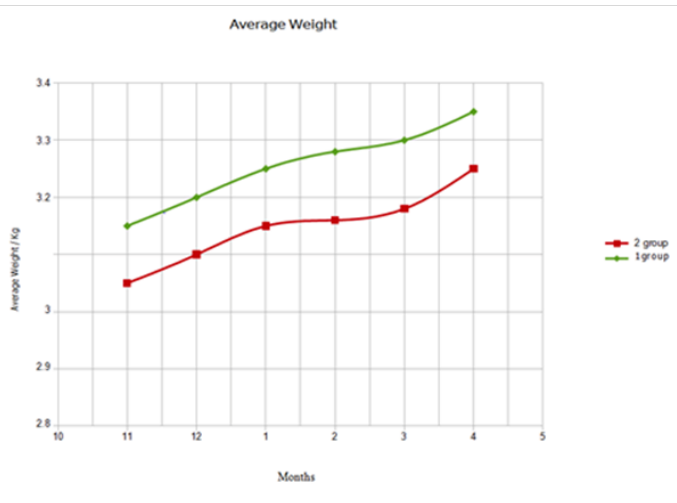

Figure I Average weight graph.

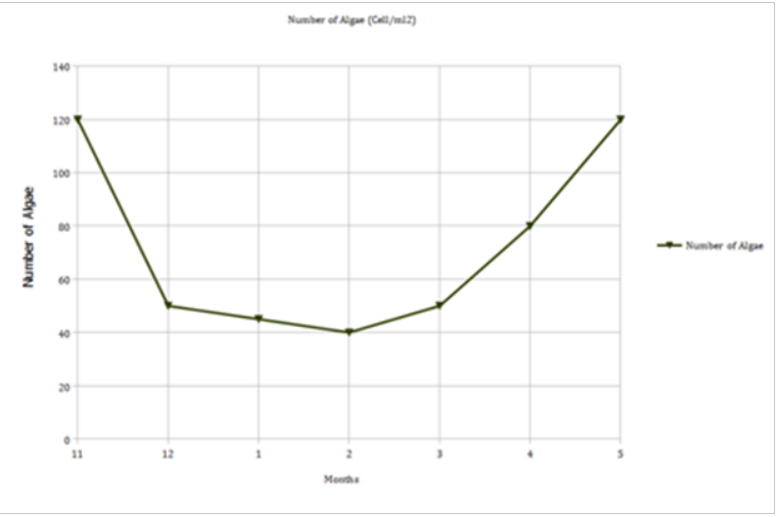

Figure 2 Algae graph.

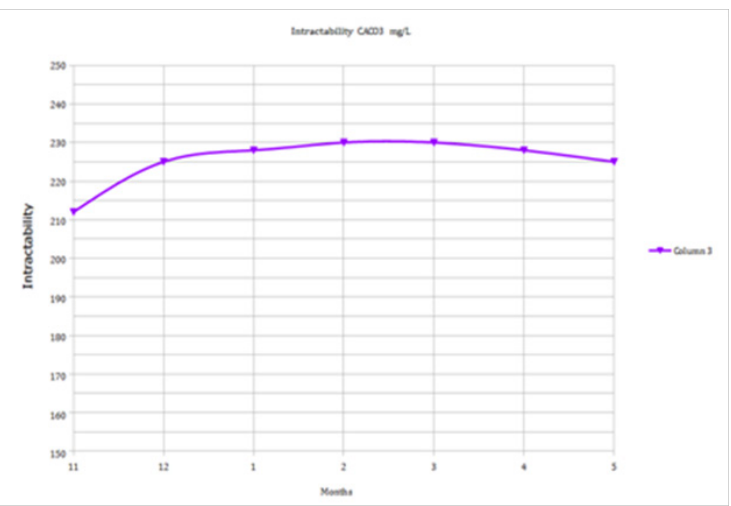

Figure 3 Intractability graph.

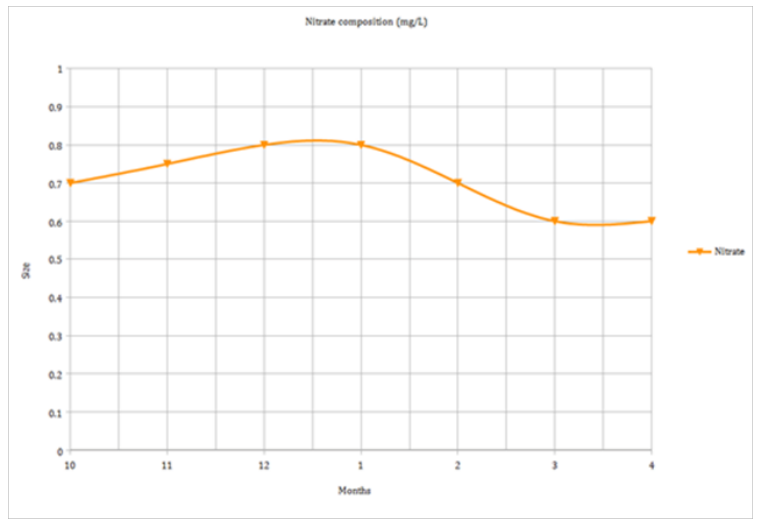

Figure $4 \mathrm{PH}$ graph.

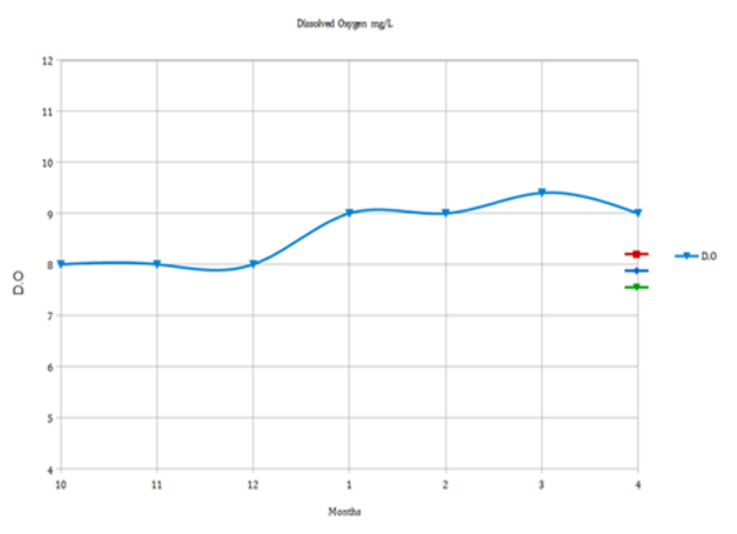

Figure 5 Dissolved oxygen graph.

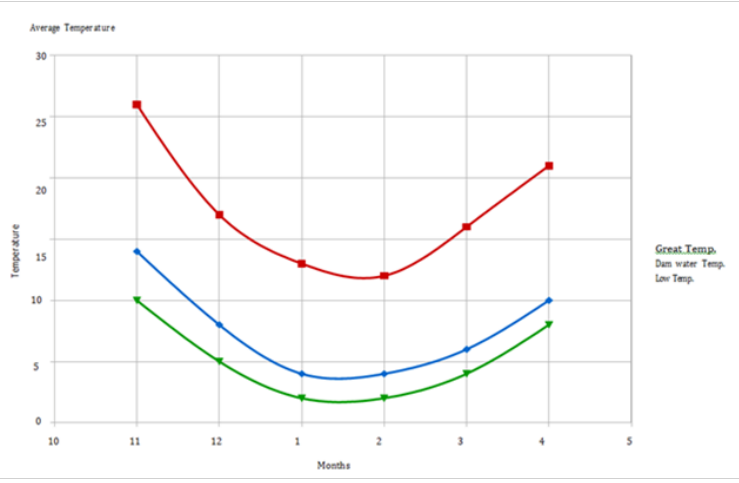

Figure 6 Average temperature graph.

Citation: Mustafa SO, Koramarky DMI, Salih SA, et al. Feeding common carp fish (cyprinus carpio) on natural foods (algae, phytoplankton, zooplankton and others) on tigris river in mosul dam / duhok, Kurdistan region of Iraq. J Aquac Mar Biol. 20 I6;4(3): I I-I2. DOI: I0.I5406/jamb.20 I6.04.00080 


\section{Discussion}

In our study there weren't significantly differences in weight and it has no obvious explanation because of difference in species of phytoplankton and zooplankton. It is a curious result that needs further investigation. ${ }^{1-15}$

\section{Conclusion and recommendation}

From the results it is an obvious that the Natural foods (Algae, phytoplankton, zooplankton and others) have a different impact on each group of fish in terms of weight. On the other hand, study should include the species of Algae, phytoplankton and zooplankton in order to know which kind of plankton has significantly impact on increasing weight of fish. Overall it can be concluded that the addition of water that contain natural food can potentially improve nutrient digestibility of different weight of fish, reduce the cost of feed. On the other hand, for this to be achieved additional research to look at the efficiency of this natural food on nutrient digestibility of complete diets based on exact natural food is required.

\section{Future research}

They are a number of areas that require further research and some have been outlined above. The important consideration must be to match the algae, phytoplankton, zooplankton and other natural food in the combination profile of the diet. Why do algae, phytoplankton and zooplankton not give positive responses in all situations? Perhaps this reflects type, level and source of water, plankton variety to name but a few of the variables that could be investigated. Also, the international agency should help us in terms of the impact of climate change on Tigris River, appears a new species of fish, valid research and the way of set up data. Other studies could examine the following.

\section{Ackowledgments}

None.

\section{Conflicts of interst}

None.

\section{References}

1. Aquatic Animal disease significant to Australia (Identification field guide) (2nd edn). 2004

2. Fisheris Western Australia-Guidelines for seafood retailers. 2001

3. George Chan Hong Nam A growth potential in Sarawak-Guide on Metcage fish culture. 1991

4. Beveridge M Cage Aquaculture. (3rd edn), Blackwell Publishing Ltd, USA, pp. 2004;368. Bvty

5. Mustafa SO Fish Rising and Production. 2014

6. Ministry of Agriculture and Water Resources- Kurdistan Region of Iraq. (4th edn), Pamphlet.

7. Mustafa SO Fish Rising and Production. (3rd edn), Agronomist Syndicate-Duhok-Kurdistan Region of Iraq, Pamphlet. 2013

8. Beveridge MCM ( Cage and pen fish farming: carrying capacity models and environmental impact. FAO. 2013

9. Boyd CE Water quality management for pond fish culture. Developments in Aquaculture and Fisheries Science 9, Elsevier, Amsterdam, Netherlands, pp. 1982;318.

10. Cabrita E, Robles V, Herraez P Methods in reproductive aquaculture: Marine and freshwater species. CRC Press, Taylor \& Francis Group, pp. 2008;572.

11. Costa-Pierce BA Ecological Aquaculture. The evolution of blue revolution. Blackwell Science, USA, pp. 2002;382.

12. Costa-Pierce BA Ecological Aquaculture. The evolution of blue revolution. Blackwell Science, USA, pp. 2002;382.

13. Wedster CD, Lim C Nutrient requirements and feeding of finfish for aquaculture, pp. 2002;418.

14. Mustafa SO Fish Raising and Production. (3rd edn), Agronomist Syndicate-Duhok-Kurdistan Region of Iraq, Pamphlet. 2008

15. Oramary SOM ( Personal Experiences from. 2008;1994-2015. 